\title{
Revised IAP Growth Charts for Height, Weight and Body Mass Index for 5- to 18-year-old Indian Children
}

\author{
Vaman Khadilkar, Sangeeta Yadav, KKAgrawal, Suchit Tamboli, Monidipa Banerjee, *Alice Cherian,

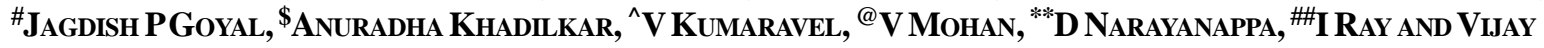 \\ YEWALE \\ From Indian Academy of Pediatrics Growth Charts Committee; *Department of Pediatrics, Lakeshore Hospital, Kochi, Kerala; \\ ${ }^{\#}$ Department of Pediatrics, AIIMS, Rishikesh, Uttarakhand, \$Hirabai Cowasji Jehangir Medical Research Institute, Jehangir \\ Hospital, Pune; ^Alpha Hospital and Research Centre, Institute of Diabetes and Endocrinology, Madurai; @Diabetes Research, \\ Dr. Mohan’s Diabetes Speciality Centre, Chennai; ${ }^{* *}$ Department of Pediatrics, JSS Medical College, JSS Univeristy, Mysuru; and \\ \#\# Department of Human Physiology, Ramakrishna Mahavidyalaya, Tripura; India. \\ Correspondence to: Dr Vaman Khadilkar, Convener, IAP Growth Chart Committee, Consultant Pediatric Endocrinologist, Hirabai Cowasji \\ Jehangir Medical Research Institute, Jehangir Hospital, Pune, India.vamankhadilkar@gmail.com
}

Justification: The need to revise Indian Academy of Pediatrics (IAP) growth charts for 5- to 18-year-old Indian children and adolescents was felt as India is in nutrition transition and previous IAP charts are based on data which are over two decades old.

Process: The Growth Chart Committee was formed by IAP in January 2014 to design revised growth charts. Consultative meeting was held in November 2014 in Mumbai. Studies performed on Indian children's growth, nutritional assessment and anthropometry from upper and middle socioeconomic classes in last decade were identified. Committee contacted 13 study groups; total number of children in the age group of 5 to 18 years were 87022 (54086 boys). Data from fourteen cities (Agartala, Ahmadabad, Chandigarh, Chennai, Delhi, Hyderabad, Kochi, Kolkata, Madurai, Mumbai, Mysore, Pune, Raipur and Surat) in India were collated. Data of children with weight for height $Z$ scores $>2$ SD were removed from analyses. Data on 33148 children (18170 males, 14978 females) were used to construct growth charts using Cole's LMS method.
Objectives: To construct revised IAP growth charts for 5-18 year old Indian children based on collated national data from published studies performed on apparently healthy children and adolescents in the last 10 years.

Recommendations: The IAP growth chart committee recommends these revised growth charts for height, weight and body mass index (BMI) for assessment of growth of 5-18 year old Indian children to replace the previous IAP charts; rest of the recommendations for monitoring height and weight remain as per the IAP guidelines published in 2007. To define overweight and obesity in children from 5-18 years of age, adult equivalent of 23 and 27 cut-offs presented in BMI charts may be used. IAP recommends use of WHO standards for growth assessment of children below 5 years of age.

Keywords: Adolescent, Child, Growth charts, India, Recommendation.

and obesity in children have shown that not only is there a rise in the incidence of overweight and obesity but adiposity rebound is seen at a younger age [5]. The pattern of growth in children has thus changed and hence we urgently need to update Indian growth charts.

In 2006, the World Health Organization (WHO) published the first growth standards as prescriptive charts for children under the age of 5 years to be used as a single uniform global standard; IAP and Government of India have adopted these standards for use in Indian children under 5 years of age. These standards are aspirational models which define how under-five children of the world should grow rather than how they actually grow. Many countries have since then changed their growth charts for under-five children as per the WHO Multicentre Growth Reference Study [6]. 
For children between 5-18 years of age, WHO has stated that it would not be possible to have prescriptive growth standards because environmental variables in this age group cannot be controlled for; hence, charts by the WHO for 5-18 year old children are based on statistical reconstruction of 1977 National Centre for Health Statistics data and are called growth references and not standards [7]. However, growth patterns differ amongst different populations, especially in children above the age of 5 years, as nutritional, environmental and genetic factors, and timing of puberty seem to play a major role not only in the attainment of final height but also in the characteristics of the growth curve. Hence, it is necessary to have country-specific growth charts to monitor growth of children between 5-18 years.

There are several recent reports on growth data of affluent Indian children, multicentric as well as regional, that can potentially be used as reference data; however, there is no national consensus on which charts to use [8]. While these studies have made an attempt to address the issue of monitoring growth in Indian children; to date, no unified charts have been constructed. Further, childhood obesity is a growing problem in urban India and hence

IAP Growth chart committee formed in January 2014

\begin{tabular}{|c|}
\hline$\downarrow$ \\
\hline $\begin{array}{c}\text { Thirteen studies published in indexed journals from India } \\
\text { on children's anthropometry in the last } 10 \text { years were } \\
\text { identified } \\
\downarrow\end{array}$ \\
\hline
\end{tabular}

\begin{tabular}{c}
$\downarrow$ \\
$\begin{array}{c}\text { Total children between the age of } 5 \text { and } 18 \text { was } 87022 \\
\text { (54086 males) (south 61173, center 3253, east 4507, } \\
\text { north } 7405 \text { and west 10684) }\end{array}$ \\
$\downarrow \downarrow$ \\
\hline 8143 children out of $\begin{array}{c}61173 \text { from south were randomly } \\
\text { selected }\end{array}$ \\
$\downarrow$
\end{tabular}

33991 (18630 males) were used in the final analysis

\section{$\downarrow$}

197 children removed as above or below 5 SD on CDC chart as obvious outliers

Out of remaining 33794, 646 (329 males) children were removed as they were above $+2 \mathrm{z}$ score for weight for height

Growth charts were constructed on 33148 children

FIG. 1 Flow chart of data acquisition and analysis. there is a worry about "normalizing" obese children if growth charts are prepared on these contemporary data sets. Since a lot of children around the world are showing a rising trend of increasing weight, no population is perfect on whom ideal weight charts can be constructed. Hence, a statistical approach has been suggested by experts, including the WHO [6,9]. WHO has described a method to eliminate unhealthy weights from populations by removing children who have weight to height $\mathrm{z}$ scores above +2 SD. This method eliminates children with unhealthy weights especially at the upper percentiles reducing the effect of obesity which is common in children of today, thus effectively dealing with the issue of “normalizing” obese children's weight.

Growth is an integral part of childhood and growth monitoring is critical for the assessment of health and disease in an individual child and the community as a whole. Since growth is an indicator of a child's health and nutrition, updated population-specific reference growth charts are needed [10]. Taken together, there is an urgent need to construct unified growth charts, adjusted for weight, for assessing the growth of contemporary Indian children from 5-18 years to be used together with the WHO standards ( $0-5$ years). With this aim, the IAP Growth Chart Committee (Annexure I) constructed revised IAP growth references for 5-18 year old Indian children based on collated national data from published studies from last 10 years, performed on apparently healthy 87022 children and adolescents. Comparisons of collated data with previous Indian and contemporary International studies are also presented.

\section{Methods}

A growth chart committee was formed by the IAP in January 2014 to design new growth charts for Indian children older than 5 years so that they are based on contemporary data that represents the growth of modernday Indian children. A consultative committee scrutinized the methodology, results and scientific content of the manuscript in November 2014 in Mumbai when data compilation, analysis and results became available. Studies performed on children's growth, nutritional assessment and anthropometry published in various Indexed journals in the last decade were indentified through internet based search engines viz. Google, Pubmed and Embase. The criteria used for selecting studies were as follows: Studies presenting anthropometric data on apparently healthy Indian children between the age of 5 to 18 (Fig. 1) from the upper and middle socioeconomic classes were included where height, weight and age were available for every child. Studies performed on children of lower 
socioeconomic class (data on them may not represent the optimal growth potential of children due to undernutrition) and where authors refused/ could not share data were excluded.

Using these criteria, it was found that three studies were performed to construct growth percentiles [11-13], one was primarily designed to construct waist circumference percentiles [14] but, height, weight and age were available for each child. Other studies were performed to assess incidence of underweight, overweight and obesity in school-going children [15-20]. One study was primarily aimed at comparing available growth charts in India while studying anthropometry on normal Indian school-going children [21]. The committee contacted 13 study groups who had published their data in indexed journals from 2004 onwards and requested data from apparently healthy children from upper and middle socio economic class. Out of 13 study groups that were contacted through electronic communication, phone calls and personal meetings, authors of nine studies were able to provide raw data on their study subjects (Table I).

Researchers were asked to provide raw data, including age, height, weight, socioeconomic class, region and gender in a pre-designed Microsoft excel template 2007. These raw data were then joined to form a single dataset. Total number of children from upper and middle class from 5 to 18 years was 87022 (54086 males). Data from fourteen cities (Agartala, Ahmadabad, Chandigarh, Chennai, Delhi, Hyderabad, Kochi, Kolkata, Madurai, Mumbai, Mysore, Pune, Raipur and Surat) were collated. To make the regional distribution more uniform, 8143 children out of 61173 from Southern India were randomly selected by generating random numbers in age-wise groups thus selecting approximately comparable number of children in each age group. Data from a total of 33991 (18630 males), were used in the final analysis. Using CDC standards, children above and below 5 SD scores for height, weight and body mass index (BMI) were removed as obvious outliers [22]. Fourteen children were removed as height SD score was below -5.0 SD and 2 removed as height SD was above +5 . Thirty-nine children were removed as weight SD scores were below -5 SD; no child was above +5 SD for weight. One hundred and forty-two children with BMI SD below -5SD were removed; no child had BMI SD above +5 .

Method used to remove children with unhealthy weights: In case of cross sectional data WHO recommends removing observations that are above +2SD of the study population for weight for height as unhealthy overweight [6]. Weight for height $\mathrm{z}$ scores were computed using Cole's LMS method. Children who were above +2 SD scores were removed from analysis. A total of 646 children (329 males) were removed from analysis. We

TABLE I PuBlished SOURCES OF RAW DATA

\begin{tabular}{|c|c|c|c|}
\hline Study title & Journal & of publication & Total children \\
\hline \multicolumn{4}{|l|}{ Cross-sectional Growth Curves for Height, Weight and Body } \\
\hline Mass Index for Affluent Indian Children, 2007[11] & Indian Pediatrics & 2009 & 18666 \\
\hline Mysore Childhood Obesity Study[16] & Indian Pediatrics & 2009 & 43152 \\
\hline $\begin{array}{l}\text { Determinants of Overweight and Obesity in Affluent Adolescent } \\
\text { in Surat City, South Gujarat Region, India [17] }\end{array}$ & $\begin{array}{l}\text { Indian Journal of } \\
\text { Community Medicine }\end{array}$ & 2011 & 5664 \\
\hline $\begin{array}{l}\text { Body Mass Index Cut-offs for Screening for Childhood } \\
\text { Overweight and Obesity in Indian Children[12] }\end{array}$ & Indian Pediatrics & 2012 & 18666 \\
\hline $\begin{array}{l}\text { Prevalence of Obesity and Overweight in Urban School Children } \\
\text { in Kerala, India[18] }\end{array}$ & Indian Pediatrics & 2012 & 1634 \\
\hline $\begin{array}{l}\text { An anthropometric study on the children of Tripura: } \\
\text { Nutritional and health coverage and redefining WHO percentile } \\
\text { cut-off points[20] }\end{array}$ & $\begin{array}{l}\text { International Journal of } \\
\text { Scientific and Research } \\
\text { Publications }\end{array}$ & 2013 & 9498 \\
\hline $\begin{array}{l}\text { Are the current Indian growth charts really representative? } \\
\text { Analysis of anthropometric assessment of school children in a } \\
\text { South Indian district[21] }\end{array}$ & $\begin{array}{l}\text { Indian Journal of Endo- } \\
\text { crinology and Metabolism }\end{array}$ & 2014 & 19668 \\
\hline $\begin{array}{l}\text { Prevalence of Overweight and Obesity Among School Children } \\
\text { and Adolescents in Chennai[19] }\end{array}$ & Indian Pediatrics & 2014 & 18955 \\
\hline $\begin{array}{l}\text { Waist Circumference Percentiles in 2-18 Year Old Indian } \\
\text { Children[14] }\end{array}$ & American Journal of Pediatrics & 2014 & 10842 \\
\hline
\end{tabular}


TABLE II Height (cm) Centiles and Standard Deviation FOR BOYS

\begin{tabular}{lllllllll}
\hline Age & 3 & 10 & 25 & 50 & 75 & 90 & 97 & $S D$ \\
\hline 5.0 & 99.0 & 102.3 & 105.6 & 108.9 & 112.4 & 115.9 & 119.4 & 5.7 \\
5.5 & 101.6 & 105.0 & 108.4 & 111.9 & 115.4 & 119.0 & 122.7 & 5.3 \\
6.0 & 104.2 & 107.7 & 111.2 & 114.8 & 118.5 & 122.2 & 126.0 & 5.6 \\
6.5 & 106.8 & 110.4 & 114.0 & 117.8 & 121.6 & 125.4 & 129.3 & 5.5 \\
7.0 & 109.3 & 113.0 & 116.8 & 120.7 & 124.6 & 128.6 & 132.6 & 5.9 \\
7.5 & 111.8 & 115.7 & 119.6 & 123.5 & 127.6 & 131.7 & 135.9 & 5.7 \\
8.0 & 114.3 & 118.2 & 122.3 & 126.4 & 130.5 & 134.8 & 139.1 & 6.3 \\
8.5 & 116.7 & 120.8 & 124.9 & 129.1 & 133.4 & 137.8 & 142.2 & 6.1 \\
9.0 & 119.0 & 123.2 & 127.5 & 131.8 & 136.3 & 140.7 & 145.3 & 6.4 \\
9.5 & 121.3 & 125.6 & 130.0 & 134.5 & 139.1 & 143.7 & 148.3 & 6.4 \\
10.0 & 123.6 & 128.1 & 132.6 & 137.2 & 141.9 & 146.6 & 151.4 & 6.8 \\
10.5 & 125.9 & 130.5 & 135.2 & 139.9 & 144.7 & 149.5 & 154.4 & 6.5 \\
11.0 & 128.2 & 133.0 & 137.8 & 142.7 & 147.6 & 152.5 & 157.5 & 7.6 \\
11.5 & 130.7 & 135.6 & 140.6 & 145.5 & 150.5 & 155.6 & 160.6 & 7.3 \\
12.0 & 133.2 & 138.3 & 143.3 & 148.4 & 153.5 & 158.6 & 163.7 & 8.1 \\
12.5 & 135.7 & 141.0 & 146.2 & 151.4 & 156.5 & 161.7 & 166.8 & 7.9 \\
13.0 & 138.3 & 143.7 & 149.0 & 154.3 & 159.5 & 164.7 & 169.9 & 9.0 \\
13.5 & 140.9 & 146.4 & 151.8 & 157.2 & 162.4 & 167.6 & 172.7 & 8.4 \\
14.0 & 143.4 & 149.0 & 154.5 & 159.9 & 165.1 & 170.3 & 175.4 & 9.0 \\
14.5 & 145.8 & 151.5 & 157.0 & 162.3 & 167.6 & 172.7 & 177.7 & 7.8 \\
15.0 & 148.0 & 153.7 & 159.2 & 164.5 & 169.7 & 174.8 & 179.7 & 7.9 \\
15.5 & 150.0 & 155.7 & 161.2 & 166.5 & 171.6 & 176.5 & 181.4 & 6.6 \\
16.0 & 151.8 & 157.4 & 162.9 & 168.1 & 173.1 & 178.0 & 182.7 & 7.2 \\
16.5 & 153.4 & 159.1 & 164.5 & 169.6 & 174.5 & 179.3 & 183.8 & 6.7 \\
17.0 & 155.0 & 160.6 & 165.9 & 171.0 & 175.8 & 180.4 & 184.8 & 6.9 \\
17.5 & 156.6 & 162.1 & 167.3 & 172.3 & 177.0 & 181.5 & 185.8 & 6.1 \\
18.0 & 158.1 & 163.6 & 168.7 & 173.6 & 178.2 & 182.5 & 186.7 & 6.9 \\
\hline
\end{tabular}

examined (using one way ANOVA) gender- and age group-wise regional differences, which showed that while there were significant differences in younger age groups amongst regions, there were no differences in height and weight SD scores post-puberty at 17 and 18 years between the five zones.

Cole's LMS method was then used to compute growth curves for height, weight and BMI using LMS method. LMS method constructs growth reference percentiles adjusted for skewness [23]. Each growth reference is summarized by three smooth curves plotted against age representing the median $(\mathrm{M})$, the coefficient of variation (S) and the skewness ( $\mathrm{L}$ ) of the measurement distribution. For height and weight 3rd, 10th, 25th, 50th, 75th, 90th and 97th percentiles were generated. Body mass index (BMI) was calculated as weight in $\mathrm{Kg}$ /height
TABLE III Weight (Kg) Centiles and Standard Deviation FOR BOYS

\begin{tabular}{lllllllll}
\hline Age & 3 & 10 & 25 & 50 & 75 & 90 & 97 & $S D$ \\
\hline 5.0 & 13.2 & 14.3 & 15.6 & 17.1 & 19.0 & 21.3 & 24.2 & 3.2 \\
5.5 & 13.8 & 15.0 & 16.5 & 18.2 & 20.3 & 22.9 & 26.1 & 2.9 \\
6.0 & 14.5 & 15.8 & 17.4 & 19.3 & 21.7 & 24.6 & 28.3 & 3.6 \\
6.5 & 15.3 & 16.8 & 18.6 & 20.7 & 23.3 & 26.6 & 30.8 & 3.8 \\
7.0 & 16.0 & 17.6 & 19.6 & 21.9 & 24.9 & 28.6 & 33.4 & 4.2 \\
7.5 & 16.7 & 18.5 & 20.7 & 23.3 & 26.6 & 30.8 & 36.2 & 4.9 \\
8.0 & 17.5 & 19.5 & 21.9 & 24.8 & 28.5 & 33.2 & 39.4 & 5.7 \\
8.5 & 18.3 & 20.5 & 23.2 & 26.4 & 30.5 & 35.7 & 42.6 & 6.5 \\
9.0 & 19.1 & 21.5 & 24.3 & 27.9 & 32.3 & 38.0 & 45.5 & 6.3 \\
9.5 & 19.9 & 22.4 & 25.6 & 29.4 & 34.3 & 40.5 & 48.6 & 7.0 \\
10.0 & 20.7 & 23.5 & 26.9 & 31.1 & 36.3 & 43.0 & 51.8 & 7.9 \\
10.5 & 21.6 & 24.6 & 28.3 & 32.8 & 38.5 & 45.8 & 55.2 & 8.3 \\
11.0 & 22.6 & 25.9 & 29.8 & 34.7 & 40.9 & 48.7 & 58.7 & 8.9 \\
11.5 & 23.8 & 27.3 & 31.6 & 36.9 & 43.5 & 51.8 & 62.5 & 9.3 \\
12.0 & 24.9 & 28.7 & 33.3 & 39.0 & 46.0 & 54.8 & 66.1 & 10.0 \\
12.5 & 26.1 & 30.2 & 35.1 & 41.2 & 48.6 & 57.8 & 69.5 & 10.6 \\
13.0 & 27.5 & 31.8 & 37.0 & 43.3 & 51.1 & 60.7 & 72.6 & 11.3 \\
13.5 & 29.0 & 33.6 & 39.1 & 45.7 & 53.8 & 63.6 & 75.6 & 11.4 \\
14.0 & 30.7 & 35.5 & 41.3 & 48.2 & 56.4 & 66.3 & 78.3 & 12.1 \\
14.5 & 32.6 & 37.7 & 43.7 & 50.8 & 59.1 & 69.1 & 80.9 & 11.6 \\
15.0 & 34.5 & 39.8 & 45.9 & 53.1 & 61.6 & 71.5 & 83.1 & 12.1 \\
15.5 & 36.1 & 41.6 & 47.9 & 55.2 & 63.6 & 73.4 & 84.7 & 11.2 \\
16.0 & 37.5 & 43.1 & 49.5 & 56.8 & 65.2 & 74.8 & 85.8 & 12.2 \\
16.5 & 38.7 & 44.4 & 50.9 & 58.2 & 66.6 & 76.1 & 86.8 & 12.6 \\
17.0 & 39.8 & 45.6 & 52.1 & 59.5 & 67.8 & 77.1 & 87.5 & 12.3 \\
17.5 & 40.8 & 46.7 & 53.2 & 60.6 & 68.7 & 77.8 & 88.0 & 12.3 \\
18.0 & 41.8 & 47.7 & 54.3 & 61.6 & 69.7 & 78.6 & 88.4 & 11.3 \\
\hline & & & & & & & &
\end{tabular}

in meters square. For the BMI; however, using International Obesity Task Force (IOTF) approach 3rd, 5th, 10th, 25th, 50th, 23 adult equivalent (as overweight cut-off), and 27 adult equivalent (as obesity cut-off) percentiles were generated as per recent recommendations for Asian Indian overweight and obesity cut offs $[24,25]$. The 3rd percentile was used to define thinness [26].

\section{Results}

Data on 33148 children were used in the construction of growth charts. Region wise distribution was 7227 (4514 boys, 2713 girls), 7835 (4263 boys, 3572 girls), 4408 (2131 boys, 2277 girls), 10474 (5473 boys, 5001 girls), 3204 (1789 boys, 1415 girls) from North, South, East, West and Central zones, respectively. Of the studies 
TABLE IVHeight (CM) Centiles and Standard DeViations FOR GIRLS

\begin{tabular}{lllllllll}
\hline Age & 3 & 10 & 25 & 50 & 75 & 90 & 97 & $S D$ \\
\hline 5.0 & 97.2 & 100.5 & 103.9 & 107.5 & 111.3 & 115.2 & 119.3 & 5.4 \\
5.5 & 99.8 & 103.2 & 106.8 & 110.5 & 114.4 & 118.3 & 122.5 & 5.7 \\
6.0 & 102.3 & 106.0 & 109.7 & 113.5 & 117.4 & 121.5 & 125.6 & 5.8 \\
6.5 & 104.9 & 108.7 & 112.5 & 116.5 & 120.5 & 124.6 & 128.7 & 5.5 \\
7.0 & 107.4 & 111.4 & 115.4 & 119.4 & 123.5 & 127.7 & 131.9 & 6.1 \\
7.5 & 110.0 & 114.1 & 118.2 & 122.4 & 126.6 & 130.8 & 135.0 & 6.0 \\
8.0 & 112.6 & 116.8 & 121.1 & 125.4 & 129.6 & 133.9 & 138.1 & 6.2 \\
8.5 & 115.2 & 119.6 & 124.0 & 128.4 & 132.7 & 137.0 & 141.3 & 6.8 \\
9.0 & 117.8 & 122.4 & 126.9 & 131.4 & 135.8 & 140.2 & 144.5 & 6.9 \\
9.5 & 120.5 & 125.2 & 129.9 & 134.4 & 138.9 & 143.3 & 147.6 & 6.6 \\
10.0 & 123.3 & 128.1 & 132.8 & 137.4 & 142.0 & 146.4 & 150.8 & 7.8 \\
10.5 & 126.1 & 130.9 & 135.7 & 140.4 & 145.0 & 149.5 & 153.9 & 7.3 \\
11.0 & 128.8 & 133.7 & 138.6 & 143.3 & 147.9 & 152.4 & 156.8 & 7.9 \\
11.5 & 131.5 & 136.4 & 141.2 & 145.9 & 150.6 & 155.1 & 159.6 & 7.1 \\
12.0 & 134.0 & 138.9 & 143.7 & 148.4 & 153.0 & 157.5 & 162.0 & 7.0 \\
12.5 & 136.3 & 141.1 & 145.8 & 150.5 & 155.1 & 159.6 & 164.1 & 6.7 \\
13.0 & 138.2 & 142.9 & 147.6 & 152.2 & 156.8 & 161.3 & 165.9 & 6.9 \\
13.5 & 139.9 & 144.5 & 149.1 & 153.6 & 158.2 & 162.7 & 167.2 & 6.0 \\
14.0 & 141.3 & 145.8 & 150.2 & 154.7 & 159.2 & 163.7 & 168.2 & 6.6 \\
14.5 & 142.4 & 146.8 & 151.1 & 155.5 & 160.0 & 164.5 & 169.0 & 5.9 \\
15.0 & 143.3 & 147.5 & 151.8 & 156.1 & 160.5 & 165.0 & 169.5 & 6.6 \\
15.5 & 144.1 & 148.1 & 152.3 & 156.6 & 160.9 & 165.3 & 169.8 & 5.9 \\
16.0 & 144.7 & 148.6 & 152.7 & 156.9 & 161.2 & 165.6 & 170.1 & 6.1 \\
16.5 & 145.2 & 149.1 & 153.1 & 157.2 & 161.4 & 165.7 & 170.2 & 6.4 \\
17.0 & 145.7 & 149.5 & 153.4 & 157.4 & 161.6 & 165.9 & 170.4 & 6.5 \\
17.5 & 146.2 & 149.8 & 153.6 & 157.6 & 161.7 & 166.0 & 170.5 & 6.7 \\
18.0 & 146.6 & 150.2 & 153.9 & 157.8 & 161.9 & 166.1 & 170.6 & 6.6 \\
\hline & & & & & & & &
\end{tabular}

excluded, growth percentile data for comparison were available in only one study and the difference in median height in boys and girls at 18 years on comparison with current study results was $<1 \mathrm{~cm}$ [13].

Fig. 2 shows the smoothed height and weight curves for Indian boys, using 3rd, 10th, 25th, 50th, 75th, 90th and 97th percentiles, respectively. Equivalent height and weight percentile values along with standard deviations are presented in Table II and Table III, respectively. Fig. 3 shows the smoothed height and weight curves for Indian girls, using 3rd, 10th, 25th, 50th, 75th, 90th and 97th percentiles, respectively. Equivalent height and weight percentile values along with standard deviations are presented in Table IV and Table V, respectively. Fig. 4 shows the smoothed BMI percentile curves for
TABLE V Weight (Kg) Centiles and Standard DeViations FOR GIRLS

\begin{tabular}{lllllllll}
\hline Age & 3 & 10 & 25 & 50 & 75 & 90 & 97 & $S D$ \\
\hline 5.0 & 12.3 & 13.4 & 14.8 & 16.4 & 18.5 & 21.3 & 25.0 & 2.5 \\
5.5 & 13.0 & 14.3 & 15.7 & 17.6 & 19.9 & 22.9 & 27.0 & 3.5 \\
6.0 & 13.7 & 15.1 & 16.7 & 18.7 & 21.3 & 24.6 & 29.1 & 3.4 \\
6.5 & 14.4 & 15.9 & 17.7 & 19.9 & 22.7 & 26.3 & 31.2 & 4.1 \\
7.0 & 15.1 & 16.8 & 18.7 & 21.2 & 24.2 & 28.2 & 33.4 & 4.4 \\
7.5 & 15.9 & 17.7 & 19.9 & 22.5 & 25.9 & 30.1 & 35.7 & 4.8 \\
8.0 & 16.7 & 18.7 & 21.1 & 24.0 & 27.6 & 32.2 & 38.1 & 5.2 \\
8.5 & 17.5 & 19.7 & 22.3 & 25.5 & 29.5 & 34.4 & 40.7 & 6.4 \\
9.0 & 18.5 & 20.9 & 23.7 & 27.2 & 31.5 & 36.7 & 43.4 & 6.4 \\
9.5 & 19.5 & 22.1 & 25.3 & 29.0 & 33.6 & 39.3 & 46.3 & 6.9 \\
10.0 & 20.7 & 23.5 & 26.9 & 31.0 & 36.0 & 42.0 & 49.4 & 7.7 \\
10.5 & 22.0 & 25.1 & 28.8 & 33.2 & 38.4 & 44.8 & 52.6 & 8.3 \\
11.0 & 23.3 & 26.7 & 30.7 & 35.4 & 41.0 & 47.7 & 55.9 & 8.5 \\
11.5 & 24.8 & 28.4 & 32.6 & 37.6 & 43.6 & 50.6 & 59.1 & 9.1 \\
12.0 & 26.2 & 30.0 & 34.5 & 39.8 & 46.0 & 53.4 & 62.1 & 9.0 \\
12.5 & 27.6 & 31.6 & 36.3 & 41.8 & 48.2 & 55.8 & 64.8 & 9.7 \\
13.0 & 28.9 & 33.1 & 37.9 & 43.6 & 50.2 & 57.9 & 67.1 & 9.4 \\
13.5 & 30.2 & 34.4 & 39.4 & 45.1 & 51.8 & 59.7 & 69.0 & 9.8 \\
14.0 & 31.3 & 35.6 & 40.6 & 46.4 & 53.2 & 61.1 & 70.4 & 9.6 \\
14.5 & 32.3 & 36.6 & 41.7 & 47.5 & 54.3 & 62.2 & 71.4 & 9.4 \\
15.0 & 33.1 & 37.5 & 42.5 & 48.4 & 55.1 & 62.9 & 72.1 & 9.6 \\
15.5 & 34.0 & 38.3 & 43.3 & 49.1 & 55.8 & 63.5 & 72.5 & 8.7 \\
16.0 & 34.7 & 39.1 & 44.0 & 49.7 & 56.3 & 64.0 & 72.8 & 8.7 \\
16.5 & 35.5 & 39.8 & 44.7 & 50.3 & 56.9 & 64.4 & 73.1 & 9.2 \\
17.0 & 36.2 & 40.5 & 45.3 & 50.9 & 57.3 & 64.7 & 73.3 & 8.8 \\
17.5 & 36.9 & 41.1 & 46.0 & 51.5 & 57.8 & 65.0 & 73.4 & 9.5 \\
18.0 & 37.6 & 41.8 & 46.6 & 52.0 & 58.2 & 65.3 & 73.5 & 10.2 \\
\hline & & & & & & & &
\end{tabular}

boys showing 3rd, 5th, 10th, 25th, 50th, 23 adult equivalent (overweight) and 27 adult equivalent (obesity) percentiles. Equivalent values for BMI for boys along with SD are shown in Table VI. Fig. 5 shows the smoothed BMI percentile curves for girls showing 3rd, 5th, 10th, 25th, 50th, 23 adult equivalent (overweight) and 27 adult equivalent (obesity) percentiles. Equivalent values for BMI for girls along with SD are shown in Table VII.

Web Table I and Web Table II illustrate the comparison of height and weight in the current study with data from Saudi Arabia [27], China [28] , IAP 2007 [1], CDC [29] and WHO [7]. The height percentiles of boys and girls from current study were almost at par with China and Saudi Arabia but were still lower than the 


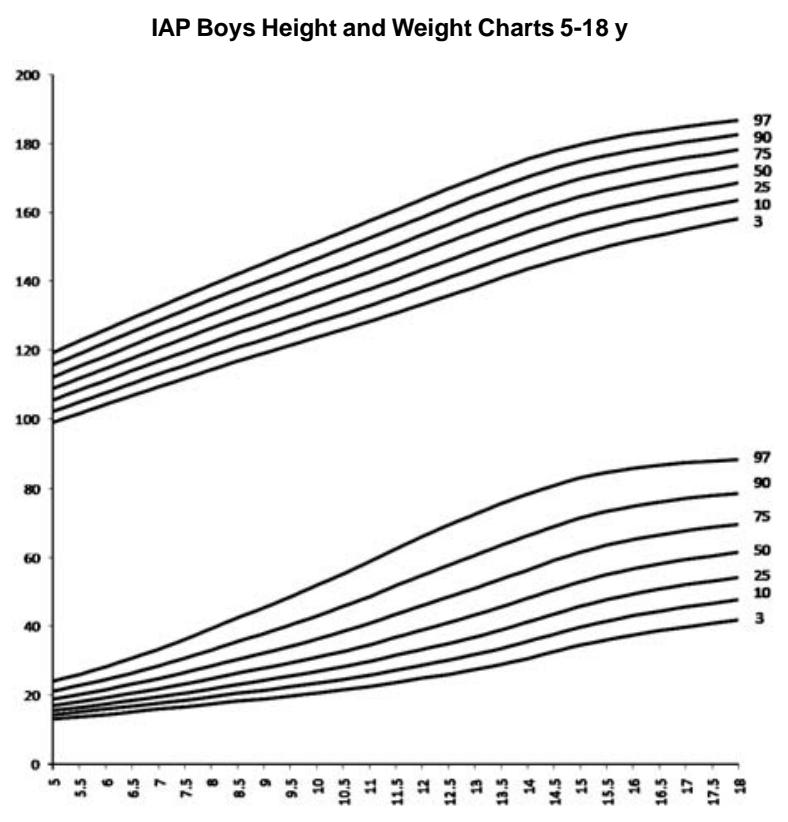

FIG. 2 Height and weight charts for boys.

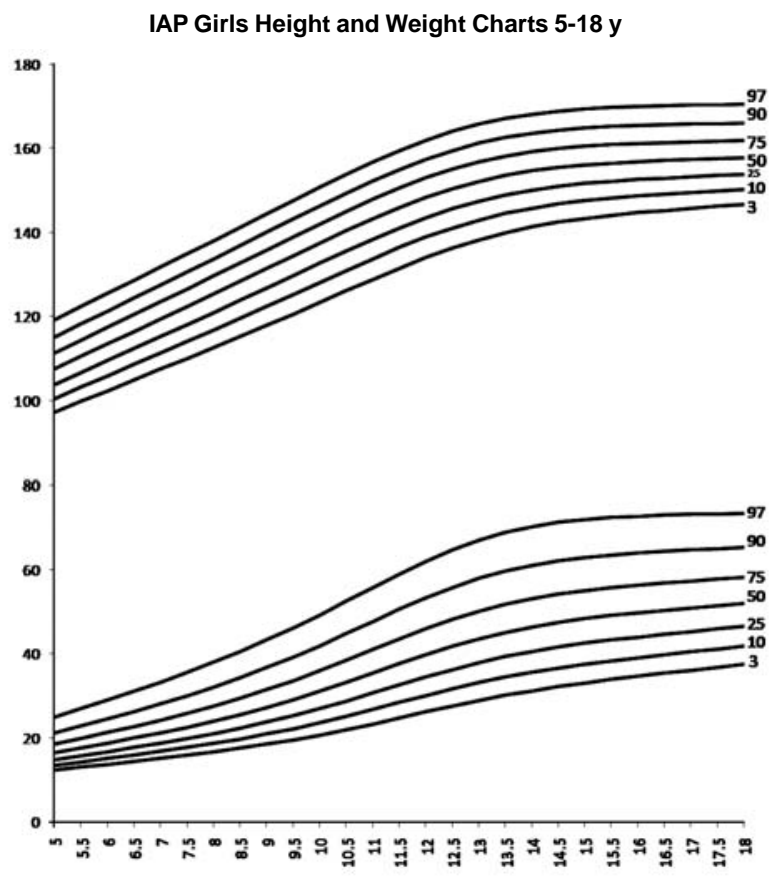

Fig. 3 Height and weight charts for girls.

CDC and WHO percentiles. Further, mean boys' height at the age of 18 year was found to be $2.8 \mathrm{~cm}$ higher than the mean as per the previous IAP growth charts, and the 97th percentile was also higher $(186.7 \mathrm{~cm} v s 181.6 \mathrm{~cm})$. In case of girls, the average height at the age of 18 year

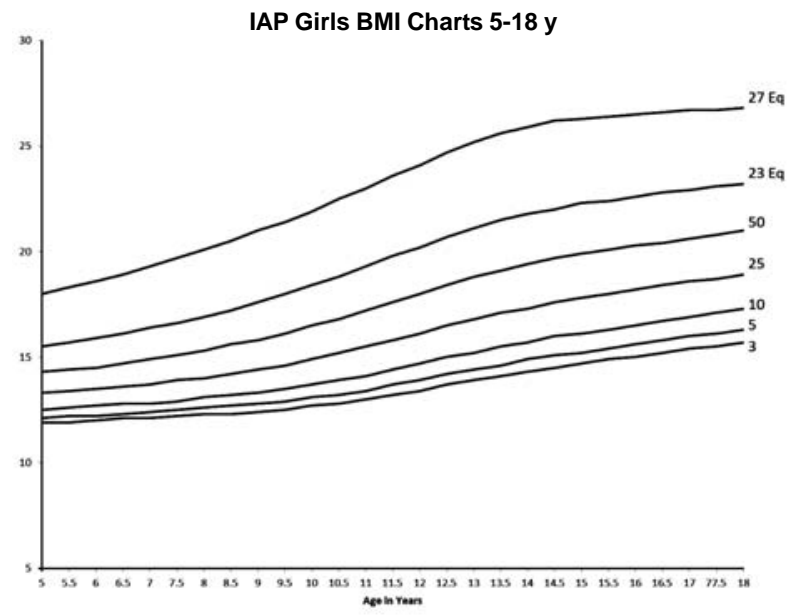

FIG. 4 Body mass index charts for boys.

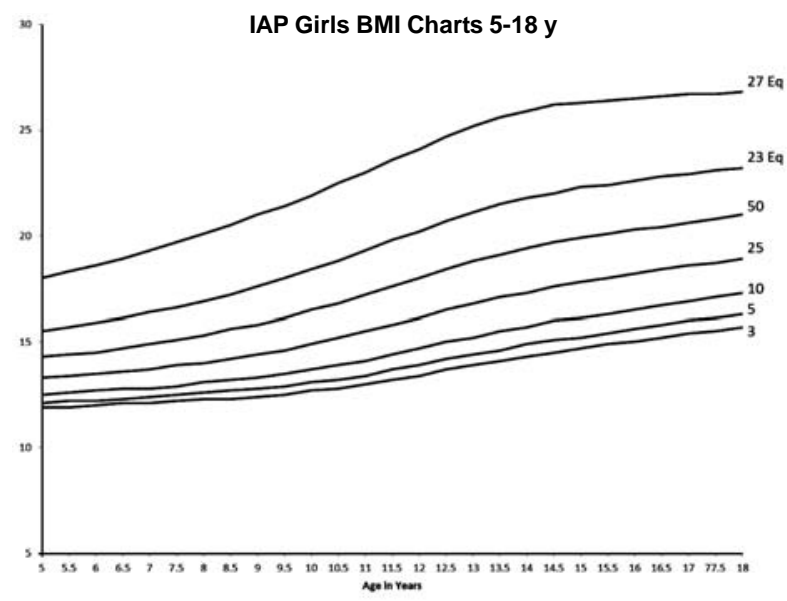

Fig. 5 Body mass index charts for girls.

showed an increase of $0.8 \mathrm{~cm}$ from 157.0 to 157.8 while the 97th percentile showed an increase of $2.6 \mathrm{~cm}$ from 168.0 to 170.6 , thus there was a secular trend in height which was more marked in boys. The upper weight percentiles in the current study are higher than IAP 2007 growth data for boys but comparable in girls, are lower than Saudi Arabia, China and CDC in case of boys and at par with Saudi Arabia and China but lower than CDC in case of girls.

\section{Discussion}

We present here cross-sectional reference percentiles curves for height, weight and BMI based on data published on 5-18 year old apparently healthy Indian children from 14 Indian cities collected by nine research groups over the last decade. As compared to the previous IAP charts, boys and girls were taller at a younger age. At 18 years, average height of boys was $2.8 \mathrm{~cm}$ higher 
TABLE VI Body Mass Index Percentiles and Standard DEVIATIONS FOR BOYS

\begin{tabular}{lllllllll}
\hline Age & 3 & 5 & 10 & 25 & 50 & 23 & 27 & $S D$ \\
& & & & & \multicolumn{4}{l}{ Eq(71) $E q(90)$} \\
\hline 5.0 & 12.1 & 12.4 & 12.8 & 13.6 & 14.7 & 15.7 & 17.5 & 1.6 \\
5.5 & 12.2 & 12.4 & 12.9 & 13.7 & 14.8 & 15.8 & 17.6 & 1.5 \\
6.0 & 12.2 & 12.5 & 12.9 & 13.7 & 14.9 & 16.0 & 17.8 & 1.8 \\
6.5 & 12.3 & 12.5 & 13.0 & 13.8 & 15.0 & 16.1 & 18.0 & 1.8 \\
7.0 & 12.3 & 12.6 & 13.1 & 13.9 & 15.1 & 16.3 & 18.2 & 1.9 \\
7.5 & 12.4 & 12.7 & 13.2 & 14.1 & 15.3 & 16.5 & 18.5 & 2.2 \\
8.0 & 12.5 & 12.8 & 13.3 & 14.2 & 15.5 & 16.7 & 18.8 & 2.5 \\
8.5 & 12.6 & 12.9 & 13.4 & 14.4 & 15.7 & 17.0 & 19.2 & 2.8 \\
9.0 & 12.7 & 13.0 & 13.5 & 14.5 & 15.9 & 17.3 & 19.6 & 2.6 \\
9.5 & 12.8 & 13.1 & 13.7 & 14.7 & 16.2 & 17.6 & 20.1 & 2.8 \\
10.0 & 12.9 & 13.2 & 13.8 & 14.9 & 16.4 & 18.0 & 20.5 & 3.1 \\
10.5 & 13.0 & 13.3 & 14.0 & 15.1 & 16.7 & 18.3 & 21.0 & 3.2 \\
11.0 & 13.1 & 13.5 & 14.1 & 15.4 & 17.0 & 18.7 & 21.5 & 3.2 \\
11.5 & 13.2 & 13.6 & 14.3 & 15.6 & 17.3 & 19.1 & 22.1 & 3.3 \\
12.0 & 13.3 & 13.8 & 14.5 & 15.8 & 17.7 & 19.5 & 22.6 & 3.4 \\
12.5 & 13.5 & 13.9 & 14.6 & 16.0 & 17.9 & 19.8 & 23.0 & 3.6 \\
13.0 & 13.6 & 14.0 & 14.8 & 16.3 & 18.2 & 20.2 & 23.4 & 3.5 \\
13.5 & 13.7 & 14.2 & 14.9 & 16.5 & 18.5 & 20.5 & 23.8 & 3.7 \\
14.0 & 13.8 & 14.3 & 15.1 & 16.7 & 18.7 & 20.8 & 24.2 & 3.7 \\
14.5 & 14.0 & 14.5 & 15.3 & 16.9 & 19.0 & 21.1 & 24.5 & 3.5 \\
15.0 & 14.2 & 14.7 & 15.5 & 17.2 & 19.3 & 21.4 & 24.9 & 3.7 \\
15.5 & 14.4 & 14.9 & 15.8 & 17.4 & 19.6 & 21.7 & 25.2 & 3.4 \\
16.0 & 14.6 & 15.1 & 16.0 & 17.7 & 19.9 & 22.0 & 25.5 & 3.7 \\
16.5 & 14.9 & 15.4 & 16.3 & 18.0 & 20.2 & 22.4 & 25.8 & 3.8 \\
17.0 & 15.1 & 15.6 & 16.6 & 18.3 & 20.5 & 22.6 & 26.0 & 3.8 \\
17.5 & 15.4 & 15.9 & 16.8 & 18.6 & 20.8 & 22.9 & 26.3 & 3.6 \\
18.0 & 15.6 & 16.2 & 17.1 & 18.9 & 21.1 & 23.2 & 26.6 & 3.2 \\
\hline & & & & & & & &
\end{tabular}

and the 97th percentile was $5 \mathrm{~cm}$ higher; for girls these figures were $0.8 \mathrm{~cm}$ and $2.6 \mathrm{~cm}$. Thus, there was a secular trend in height which underlines the importance of updating growth charts in a developing nation like India.

By adopting the approach as suggested by the WHO, it was possible to produce weight percentiles which were lower as compared to the recently published weight charts on affluent Indian children in 2011, thus reducing the impact of unhealthy weights on growth charts. At 5,10 and 18 years the 97th percentile was 5.3, 1.5 and $10.1 \mathrm{~kg}$ lower in comparison with the 2011 data, respectively, while the difference in the median at 5, 10, 18 years was $1.9,1.9$ and $4.7 \mathrm{~kg}$, respectively in boys [6,13]. In girls, the equivalent values at 5, 10 and 18
TABLE VII Body Mass Index Percentiles and Standard DEVIATIONS FOR GIRLS

\begin{tabular}{lllllllll}
\hline Age & 3 & 5 & 10 & 25 & 50 & 23 & 27 & $S D$ \\
& & & & & \multicolumn{4}{l}{ Eq(75) } \\
Eq(95) \\
\hline 5.0 & 11.9 & 12.1 & 12.5 & 13.3 & 14.3 & 15.5 & 18.0 & 1.4 \\
5.5 & 11.9 & 12.2 & 12.6 & 13.4 & 14.4 & 15.7 & 18.3 & 1.7 \\
6.0 & 12.0 & 12.2 & 12.7 & 13.5 & 14.5 & 15.9 & 18.6 & 1.7 \\
6.5 & 12.1 & 12.3 & 12.8 & 13.6 & 14.7 & 16.1 & 18.9 & 2.0 \\
7.0 & 12.1 & 12.4 & 12.8 & 13.7 & 14.9 & 16.4 & 19.3 & 2.1 \\
7.5 & 12.2 & 12.5 & 12.9 & 13.9 & 15.1 & 16.6 & 19.7 & 2.2 \\
8.0 & 12.3 & 12.6 & 13.1 & 14.0 & 15.3 & 16.9 & 20.1 & 2.3 \\
8.5 & 12.3 & 12.7 & 13.2 & 14.2 & 15.6 & 17.2 & 20.5 & 2.7 \\
9.0 & 12.4 & 12.8 & 13.3 & 14.4 & 15.8 & 17.6 & 21.0 & 2.7 \\
9.5 & 12.5 & 12.9 & 13.5 & 14.6 & 16.1 & 18.0 & 21.4 & 2.8 \\
10.0 & 12.7 & 13.1 & 13.7 & 14.9 & 16.5 & 18.4 & 21.9 & 2.9 \\
10.5 & 12.8 & 13.2 & 13.9 & 15.2 & 16.8 & 18.8 & 22.5 & 3.1 \\
11.0 & 13.0 & 13.4 & 14.1 & 15.5 & 17.2 & 19.3 & 23.0 & 3.1 \\
11.5 & 13.2 & 13.7 & 14.4 & 15.8 & 17.6 & 19.8 & 23.6 & 3.3 \\
12.0 & 13.4 & 13.9 & 14.7 & 16.1 & 18.0 & 20.2 & 24.1 & 3.2 \\
12.5 & 13.7 & 14.2 & 15.0 & 16.5 & 18.4 & 20.7 & 24.7 & 3.3 \\
13.0 & 13.9 & 14.4 & 15.2 & 16.8 & 18.8 & 21.1 & 25.2 & 3.2 \\
13.5 & 14.1 & 14.6 & 15.5 & 17.1 & 19.1 & 21.5 & 25.6 & 3.5 \\
14.0 & 14.3 & 14.9 & 15.7 & 17.3 & 19.4 & 21.8 & 25.9 & 3.4 \\
14.5 & 14.5 & 15.1 & 16.0 & 17.6 & 19.7 & 22.0 & 26.2 & 3.3 \\
15.0 & 14.7 & 15.2 & 16.1 & 17.8 & 19.9 & 22.3 & 26.3 & 3.4 \\
15.5 & 14.9 & 15.4 & 16.3 & 18.0 & 20.1 & 22.4 & 26.4 & 3.1 \\
16.0 & 15.0 & 15.6 & 16.5 & 18.2 & 20.3 & 22.6 & 26.5 & 3.1 \\
16.5 & 15.2 & 15.8 & 16.7 & 18.4 & 20.4 & 22.8 & 26.6 & 3.2 \\
17.0 & 15.4 & 16.0 & 16.9 & 18.6 & 20.6 & 22.9 & 26.7 & 3.0 \\
17.5 & 15.5 & 16.1 & 17.1 & 18.7 & 20.8 & 23.1 & 26.7 & 3.1 \\
& 15.7 & 16.3 & 17.3 & 18.9 & 21.0 & 23.2 & 26.8 & 3.6 \\
\hline & & & & & & & &
\end{tabular}

years were $3.7,3.3$ and $6.6 \mathrm{~kg}$ at the 97th percentile, respectively and at 5, 10 and 18 years 2.1, 2.8 and 3.6 $\mathrm{kg}$, respectively at the median. The same comparison with affluent Indian children data published in 2009 shows that in boys the difference in 97th percentile at 5 , 10,18 years was $1.9,3$ and $9.9 \mathrm{~kg}$ while the difference in the median was unremarkable. In girls, equivalent values at 5,10 and 18 years were $0.3,3.9$ and $9.1 \mathrm{kgs}$ at the $97 \mathrm{th}$ percentile while the difference in median was insignificant [11]. Thus the study reduced the impact of unhealthy weights on the weight charts.

BMI charts presented are based on the same method as IOTF [24]. The 23 and 27 adult equivalent cut offs lines (for risk of overweight and obesity, respectively) are more appropriate for use in Asian children as Asians 
are known to have more adiposity and increased cardiometabolic risk at a lower BMI [25]. The current study's 23 and 27 adult equivalent cut-offs are very close to IOTF's extended 23 and 27 cut-offs for both sexes, being slightly lower than the IOTF extended Asian cut-offs by about 0.5 in the 23rd equivalent line and by about 1 in the 27 equivalent line in boys. In case of girls the 23 and 27 equivalent lines are similar [24].

Comparing the final height and weight data with recent international studies from China, Saudi Arabia, WHO and CDC, it is clear that Indian children are growing almost at par with Chinese and Saudi Arabian children but are still shorter and lighter than their Caucasian counterparts [7,27,28,29] (Table VII and Web Table I). Further, Indian children's stature seems to be comparable to Caucasian children until the onset of pubertal years, however, the growth spurt after puberty is attenuated in Indian children in both sexes, the effect being more pronounced in girls. Thus, the average difference in height between Caucasian girls and Indian girls from 5 to 11 years of age is only about $1 \mathrm{~cm}$; however this gap widens to $6 \mathrm{cms}$ at 18 years. Similar figures in boys are $1 \mathrm{~cm}$ from the age of 5 to 12.5 years and $3.5 \mathrm{~cm}$ at 18 years. Interestingly, Chinese children also show a very similar growth pattern suggesting that this is possibly a characteristic of Asian children [30]. These finding are of particular relevance in interpreting target height and predicting final adult height based on prediction equations, thus stressing the need for ethnic specific growth charts.

Updating growth references and standards is necessary because with changing socioeconomic standards and demographic changes children's growth patterns also change and secular trends can be incorporated in the updated growth charts. This is particularly true in a developing country as nutrition transition influences growth patterns significantly and secular trends can be marked over a short time period.

The strengths of the growth charts presented here are that they are contemporary, have good national representation as they are prepared from 14 Indian cities from all five zones of IAP giving a true representation of current growth pattern of children across the country. The BMI charts give adult equivalent cut-offs which are more relevant for Asian children and the data have been corrected for unhealthy weights. A drawback of this study is that the study designs and measurement scales possibly used in the nine studies included are different; however, rigorous attention has been given to the methodology of all studies included here to minimize errors while data analysis was performed.

\section{RECOMMENDATIONS}

The IAP Growth Chart Committee recommends these revised growth charts for height, weight and BMI for assessment of growth of 5-18 year old Indian children to replace the previous IAP growth charts; the rest of the recommendations for monitoring height and weight remain as per the IAP guidelines published in 2007. To define overweight and obesity in children from 5-18 years of age, adult equivalent of 23 and 27 cut-off lines as presented in BMI charts here may be used.

IAP recommends use of WHO Multistandards Growth Reference Study for assessment of children under the age of 5 years.

Acknowledgement: Dr Shashi Chiplonkar, Honorary Senior Scientist and Statistician HCJMRI, Jehangir Hospital, Pune, for her advice on the project.

Contributors: VK: helped in conceptualizing and designing the methodology, contributed the data, helped in data analysis and manuscript writing and will act as the corresponding author; SY, KA, ST, MB, VY: were a part of the IAP Growth Chart Committee and helped in conceptualizing and designing the study and manuscript writing; AC, JG, AK, VK, VM, DN, IR: contributed data and helped in manuscript writing.

Funding: None; Competing interests: None stated.

\section{ANNEXURE I}

IAP Growth chart committee: V Yewale (Chairperson), V Khadilkar (Convener), S Yadav, KK Agarwal, S Tamboli, M Banerjee. IAP Office Bearers: Vijay Yewale: IAP President; Sachidananda Kamath: IAP President Elect; CP Bansal: Immediate Past President; Neeli Ramchander: Vice president; Pravin Mehta: Hon Secretary General; AS Vasudev: Hon Joint Secretary; Bakul Parekh: Treasurer; Dheeraj Shah: Editor, Indian Pediatrics; P Ramachandran: Editor, Indian Journal of Practical Pediatrics; Upendra Kinjawadekar: Academic Affairs Administrator.

\section{REFERENCES}

1. Khadilkar VV, Khadilkar AV, Choudhury P, Agarwal KN, Ugra D, Shah NK. IAP growth monitoring guidelines for children from birth to 18 years. Indian Pediatr. 2007;44:187-97.

2. Agarwal DK, Agarwal KN, Upadhyay SK, Mittal R, Prakash R, Rai S. Physical and sexual growth pattern of affluent Indian children from 5-18 years of age. Indian Pediatr. 1992;29:1203-82.

3. Agarwal DK, Agarwal KN. Physical growth in Indian affluent children (Birth - 6 years). Indian Pediatr. 1994;31:377-413.

4. Buckler JMH. Growth Disorders in Children. 1st ed. London: BMJ Publishing Group; 1994.

5. Khadilkar VV, Khadilkar AV, Cole TJ, Chiplonkar SA, Pandit D. Overweight and obesity prevalence and body mass index trends in Indian children. Int J Pediatr Obes. 2011;6:e216-24. 
6. WHO Child Growth Standards. Acta Pediatr Supplement. 2006;450:5-101.

7. de Onis M, Onyango AW, Borghi E, Siyam A, Nishida C, Siekmann J. Development of a WHO growth reference for school-aged children and adolescents. Bull World Health Organ. 2007;85:660-7.

8. Khadilkar V, Phanse S. Growth charts from controversy to consensus. Indian J Endocrinol Metab. 2012;16:S1857.

9. Bhatia V. Growth charts, the secular trend and the growing concern of childhood obesity. Natl Med J India. 2011;24:260-2.

10. Cameron N. The methods of auxological anthropometry. In: Falkner F, Tanner JM (eds). Human growth-A comprehensive treatise. Vol. III. 2nd ed. New York: Plenum Press; 1986. p.3-46.

11. Khadilkar VV, Khadilkar AV, Cole TJ, Sayyad MG. Cross-sectional growth curves for height, weight and body mass index for affluent Indian children, 2007. Indian Pediatr. 2009;46:477-89.

12. Khadilkar VV, Khadilkar AV, Borade AB, Chiplonkar SA. Body mass index cut-offs for screening for childhood overweight and obesity in Indian children. Indian Pediatr. 2012;49:29-34.

13. Marwaha RK, Tandon N, Ganie MA, Kanwar R, Shivaprasad C, Sabharwal A, et al. Nationwide reference data for height, weight and body mass index of Indian schoolchildren. Natl Med J India. 2011;24:269-77.

14. Khadilkar A, Ekbote V, Chiplonkar S, Khadilkar V, Kajale N, Kulkarni S, et al. Waist circumference percentiles in 2-18 year old Indian children. J Pediatr. 2014;164:1358-62.

15. Kaur S, Sachdev HP, Dwivedi SN, Lakshmy R, Kapil U. Prevalence of overweight and obesity amongst school children in Delhi, India. Asia Pac J Clin Nutr. 2008;17:592-6.

16. Premanath M, Basavanagowdappa H, Shekar MA, Vikram SB, Narayanappa D. Mysore childhood obesity study. Indian Pediatr. 2010;47:171-3.

17. Goyal JP, Kumar N, Parmar I, Shah VB, Patel B. Determinants of overweight and obesity in affluent adolescent in Surat City, South Gujarat Region, India. Indian J Community Med. 2011;36:296-300.

18. Cherian AT, Cherian SS, Subbiah S. Prevalence of obesity and overweight in urban school children in Kerala, India. Indian Pediatr. 2012;49:475-7.
19. Jagadesan S, Harish R, Miranda P, Unnikrishnan R, Anjana RM, Mohan V. Prevalence of overweight and obesity among school children and adolescents in Chennai. Indian Pediatr. 2014;51:544-9.

20. Ray I, Amar K. An anthropometric study on the children of Tripura: Nutritional and health coverage and redefining WHO percentile cut-off points. Int J Sci Res Publi. 2013;3:1-8.

21. Kumaravel V, Shriraam V, Anitharani M, Mahadevan S, Balamurugan AN, Sathiyasekaran BW. Are the current Indian growth charts really representative? Analysis of anthropometric assessment of school children in a South Indian district. Indian J Endocrinol Metab. 2014;18: 56-62.

22. Mansourian M, Marateb HR, Kelishadi R, Motlagh ME, Aminaee T, Taslimi M, et al. First growth curves based on the World Health Organization reference in a Nationallyrepresentative sample of pediatric population in the Middle East and North Africa (MENA): the CASPIAN-III study. BMC Pediatr. 2012;12:149.

23. Cole TJ, Green PJ. Smoothing reference centile curves: The LMS method and penalized likelihood. Stat Med. 1992;11:1305-19.

24. Cole TJ, Lobstein T. Extended international (IOTF) body mass index cut-offs for thinness, overweight and obesity. Pediatr Obes. 2012;7:284-94.

25. WHO Expert Consultation. Appropriate body-mass index for Asian populations and its implications for policy and intervention strategies. Lancet. 2004;10:157-63.

26. http://www.who.int/growthref/who2007_bmi_for_age/ en/. Accessed November 13, 2014.

27. El-Mouzan MI, Al-Herbish AS, Al-Salloum AA, Qurachi MM, Al-Omar AA. Growth charts for Saudi children and adolescents. Saudi Med J. 2007;28:1555-68.

28. Zong XN, Li H. Construction of a new growth references for China based on urban Chinese children: Comparison with the WHO growth standards. PLoS One. 2013;8:e59569.

29. Kuczmarski RJ, Ogden CL, Guo SS, Grummer-Strawn LM, Flegal KM, Mei Z, et al. 2000 CDC Growth Charts for the United States: methods and development. Vital Health Stat. 11. 2002;246:1-190.

30. Li H, Ji CY, Zong XN, Zhang YQ. Height and weight standardized growth charts for Chinese children and adolescents aged 0 to 18 years. Zhonghua Er Ke Za Zhi. 2009;47:487-92. 